But in vasomotor rhinitis so many different proteins may cause trouble that it is, at present, almost impossible to identify them in any individual case. The skin tests may be tried, but they do not cover every possible source. In any case, patients' sensitiveness to various proteins changes from time to time. Attention to diet by preventing the access of offending proteins may relieve the symptoms for a time. Treatment of hay fever by pollantin (Dunbar's antitoxin) has in my hands met with no success, nor has desensitization.

\section{Summary OF Treatment}

If these allergic conditions are accompanied by other nasal pathological manifestations, they should be suitably dealt with. Occasionally an enlarged middle turbinal will be found pressing against the septum; or, more rarely, the tubercle of the septum will be so large as to form a small tumour on the septum. In these cases surgical intervention is called for. It is now my practice in treating these nasal allergic conditions to combine local and general treatment. In all cases I prescribe the use, two or three times daily, of the oily solution recommended above, and also parathyroid and calcium tablets in doses suitable to the age of the patient. If the intranasal appearances are fairly normal, I await the result of this treatment for two or three months. If any marked intranasal abnormalities are present they are dealt with at once. If the tubercle of the septum is prominent, or if the inferior turbinals are enlarged, I proceed to cauterize at once. At the end of two or three months, if no improvement has taken place, I use the electrocautery to the sensitive areas and change over from the parathyroid and calcium treatment to suprarenal pituitary.

${ }^{1}$ Mollison, W. M.: Brilish Mcdical Journal, 1929, ii, 1052.

\section{THE PROGRESS OF INSULIN DIABETICS ON A LIBERAL CARBOHYDRATE DIET} BY

\section{CHARLES S. D. DON, M.D.ABERd., M.R.C.P.LoNd.} HONORARY PHYSICIAN, SALFORD ROYAL HOSPITAL

For many years diabetic diets have been composed with a view to curtailing considerably the carbohydrates and to increasing the fat.

The formulae of Woodyatt and of Wilder are based on this underlying principle. However, Allen ${ }^{1}$ has found that fat influences the insulin requirement, and Greenwald ${ }^{2}$ and others have expressed the opinion that it lowers the carbohydrate tolerance. A high carbohydrate diet was advocated by Sansum, ${ }^{3}$ and at a meeting of the Royal Society of Medicine, in 1931, Poulton and other speakers were agreed that a higher carbohydrate diet was desirable, though Lawrence stated that in his experience, insulin reactions, as a result of the increased insulin dosage, were more frequent. Nixon ${ }^{5}$ and $D_{y k e^{6}}$ have had satisfactory results, and Richardson ${ }^{7}$ was able to increase the carbohydrate at the expense of the fat in patients, and even in a case where the carbohydrate was increased from 57 to 150 grams, and the fat reduced from 150 to 57 grams, there was no necessity to increase the insulin dosage. Himsworth $^{8}$ had results of a somewhat similar kind.

\section{The High Carbohydrate Diet}

The diets used with insulin at Salford Royal Hospital have contained a high carbohydrate content for the past six years, the caloric value varying according to the patient's normal weight. A man of average weight receives carbohydrate 165 grams, fat 126 , protein 83 ; but some women receive as little as 110 grams of carbohydrate, and a few men as much as 190 grams. I have had the opportunity of observing 171 of these cases in the diabetic clinic after their discharge from hospital, for varying periods up to six years; these patients attended about once a month, and they were taught to test their own urines at home for sugar, a procedure which made them keep to their diets to a surprising extent. A record of the weight, urinary sugar, blood sugar, and of any reactions was made at each visit, and the insulin increased or decreased as indicated.

\section{INSUlin Dosage}

For the purposes of assessing the changes in insulin dosage I have taken first the records of 94 cases, which have apparently co-operated, and have attended for at least one year, and, according to whether the daily dose has had to be increased by 8 or more units, or decreased by 8 or more units, the dose of insulin is considered to have been " increased," " stationary," or " decreased," the comparison being made between the first attendances and the last attendances, be it one year's duration or six years'. Some patients showed large variations during the first few months, yet could be classed as stationary after a year's attendance. Of these 94 cases the dose was stationary in 45 , decreased in 24 , and increased in 25 .

Duncan ${ }^{9}$ observed 64 cases for two years, and 39 showed a decrease in the insulin dosage, 8 showed an increase, and in 17 it was unchanged. I have followed 61 cases for a period of at least two years-in many cases for five or six years, the average being three years. A comparision of their first and last attendances shows that the dose was stationary in 24 cases, decreased in 17, and increased in 20. Of the 17 cases which showed a decrease, in 16 this decrease had already taken place at the end of the first year's treatment, and at the end of the second year all 17 showed a decrease as compared with the first attendances. Compared with the dose at twelve months, a further decrease had only occurred in 3 cases and an actual increase in 1 case, though the dose is still well below that given at the first attendance. Five of these 17 cases attended for four to six years, but in no case had a further alteration of more than 8 units been made in the day's dosage.

Of the 20 cases labelled " increased," this had occurred in only 7 cases at the end of one year, while at the end of two years a further increase of 8 or more units had occurred in 3 of these, but in only 10 cases was there an increase compared with the first attendances, the remaining 10 cases showing the increase in the course of three to six years. There are only 22 cases which have attended for four to six years, and a comparison of the first and last doses shows that an increase of 8 or more units has occurred in 12, a decrease in 5 , while in 5 cases the dose was stationary. I realize that reductions or increases in diet, which patients might make without my knowledge, and other variations (Rabinowitch ${ }^{10}$ ), may account for all these changes in the dose of insulin.

It was possible in many cases to reduce the injections to once daily, yet in only 19 of the 171 cases which attended the clinic was it possible to stop insulin, and in 8 of these the injections had to be restarted later owing to the reappearance of urinary sugar, but 11 have remained sugar-free up to their last visit. These 11 patients are all over 48 years of age, and the average time before insulin was stopped was six months, in 3 cases the period being one to one and a half years. They were not severe cases, the worst receiving 36 units daily at the start, the average being 20 units. I know of only one patient in the clinic who has been able to stop insulin and resume a normal diet without glycosuria reappearing; this patient gradually developed cirrhosis of the liver and ascites. Other patients may have been able to stop insulin and resume a normal diet, but simply ceased to attend. 


\section{Hypo- ANd Hyper-GLyCAEMia}

Insulin reactions are occasionally reported by patients, but, with rare exceptions, they have not been serious, and,patients are instructed to reduce the dose at once. Four patients have, however, had hypoglycaemic coma, and in one of these the onset was so rapid that she fell, and a fracture of the olecranon resulted. In one of these cases death resulted, in spite of the fact that on admission to hospital the blood sugar was restored to normal by glucose intravenously. A large dose of insulin had been given before admission, because the case was mistaken for one of hyperglycaemic coma. The patient was a woman of 20 years-a severe diabetic-and a necropsy showed an enlarged thymus, with thymus tissue on section.

Three patients with hyperglycaemia have been readmitted to the ward in coma, in one case brought on by influenza, in another by an alveolar abscess. Both these recovered, but the third died. Other cases of coma may, however, have been treated at some other hospitals and have continued attending there.

\section{Blood Pressure}

Joslin ${ }^{11}$ found the blood pressure to be lower than normal in patients under 35 , but above normal after that, anc Koopman's ${ }^{12}$ view is somewhat similar. Adams ${ }^{13}$ found that, although more cases have a systolic blood pressure above 150 than is the case in normal subjects, more cases have a systolic blood pressure under 110 than is seen in normal subjects. In Major's ${ }^{14}$ cases the peak of a graph fell between 135 and 150, while in normals it fell between 120 and 135 . Katz Klein, ${ }^{15}$ Kramer, ${ }^{16}$ Beil and Clawson, ${ }^{17}$ all found an increased blood pressure to be common. Elliott ${ }^{18}$ considered that it was normal, and Nathanson ${ }^{19}$ stated that the incidence of hypertensive hypertrophy of the heart at post-mortem indicates that hypertension is only slightly more common in diabetics than in non-diabetics.

I took the blood pressure in 60 patients who have attended over an average period of three years, and still continue, and repeated examination of those with high readings at subsequent visits. There were 32 cases with a systolic pressure above $150 \mathrm{~mm}$. of mercury, or a diastolic above $100 \mathrm{~mm}$., the average being 164 systolic and 96 diastolic. There were 28 cases with a systolic below 150 and a diastolic under 100, the average being 136 systolic and 83 diastolic. A trace of albumin was present in the urine, in 4 cases with a blood pressure over 150 and in 2 with a blood pressure below 150 . In 13 cases a moderate amount of sugar was found on the first day the blood pressure was taken, in 10 a small quantity, and in 37 sugar was absent. In 9 of the cases with frank sugar a faint trace of acetone was present. There was no relationship between the glycosuria and the blood pressure, but, of course, it is quite likely that at another visit some of those with glycosuria would be sugar-free. The urine tested was the specimen passed carly on that morning, and the chemical findings represent a fair average of the insulin patients as a whole.

These 60 cases on which I took the blood pressure were also examined for evidence of pulmonary tuberculosis. They were $x$-rayed by Dr. H. M. Morris, and in 59 cases the lungs showed no sign of tuberculosis ; in one, however, there was active disease at the right apex. This patient had been attending and having insulin for two and a half years; he was receiving 50 units daily, and, so far as his blood sugar and urinary tests showed, he kept to his diet. Joslin $^{20}$ saw 43 cases of tuberculosis of the lungs in 3,000 cases of diabetes, while Fitz ${ }^{21}$ had 35 in 1,529 cases. Tuberculosis before treatment is therefore not uncommon, but I was disappointed to find it developing in a man after two and a half years' treatment, though this may be a coincidence.

\section{Conclusions}

1. The insulin requirements for 61 cases, observed for two to six years on a liberal carbohydrate diet, show that the dose had to be reduced in 17 and increased in 20 , while in 24 no change was necessary.

2. It was possible to stop insulin in 19 out of 171 cases, but it had to be rsstarted in 8 .

3. In only one case seen in the clinic was it possible to stop insulin and return to an unrestricted diet. This patient was developing cirrhosis of the liver.

4. The blood pressure in treated cases shows an increase above a systolic pressure of $150 \mathrm{~mm}$., or a diastolic of $100 \mathrm{~mm}$. $\mathrm{Hg}$ in 32 out of 60 which have been on insulin for an average period of three years.

5. Insulin reactions cccurred occasionally, but rarely gave rise to serious results.

\section{Referexces}

${ }^{1}$ Allen, F. M.: Journ. Metab. Rescarch, 1923, iii, 61

2 Greenwald, L., Gross, J., Samet, J.: Journ. Biol. Chem., 1924, lxii, 401 .

${ }^{3}$ Sansum, W. D., Blatherwick, N. R., Bowden, R.: Journ. Amer. Med. Assoc., 1926, lxxxvi, 178

4 Roy. Soc. Med.: Lancet, 1931, i, 351.

5 Nixon, J. A.: British Medical Journal, 1930, i, 326.

'Dyke, S. C.: Lancet, 1932 , i, 978

7 Richardson, R.: Amer. Journ. Med. Sci., 1929, No. 177, 426

"Himsworth, H. P.: Lancet, 1981, ii, 978.

9 Timsworth, H. P.: Kancet. 19s1, 11, 978.

" Juncan, G. G. (quoted by Witts, L. J.): IBia., 1926, ii,

"Rabinowitch, I. M.: Quart. Journ. Med., 1928, xxi, 211.

Joslin, E. P.: Treatment of Diabctes Mellitus, 1923.

12 Koopman, J.: Endocrinology, 1924, viii, 340.

1.3 Adains, S. F.: Amer. Joum. Med. Sci., 1929, No, 177, 1 5.

'Major, S. G.: Arch. Int. Med., 1929, xliv, 797

15 Katz Klein, F.: Mcd. Klin., 1924, xx, 1808.

"Kramer, D. W.: Amer. Journ. Med. Sci., 1928, No. 176, 23.

1 Bell, I. T., and Clawson, B. J.: Arch. P'ath.. 1928, v, 939.

is Ellictt, A. R.: Journ. Amer. Med. Assoc., 1907, xlix, 27

19 Nathanson, M. H.: Amer. Journ. Med. Sci., 1932, No. 721, 495.

". Joslin, E. P.: Loc. cit., 1928.

2 Fitz, R.: Ibid., 1930, clxxx, 192.

\section{BONE ABSCESSES DUE TO BRUCELLA MELITENSIS}

BY

A. D. GARDNER, D.M.Oxon., G. R. GIRDLESTONE, F.R.C.S., AND

\section{N. A. GILLESPIE, B.M.Oxon.}

The occurrence of arthropathies and hydrarthroses complicating Mediterranean fever has been extensively noted in the medical press. Bone lesions proper have been reported, but very little stressed. In the Iowa series of 375 cases Hardy ${ }^{1}$ quotes 32 per cent. arthropathies, one case of hydrarthrosis, and one case which was operated on for osteomyelitis, and in which pus was found. In the Ohio series of 175 cases, Simpson ${ }^{2}$ finds 31 per cent. arthropathies. Baker ${ }^{3}$ has reported a very interesting case of intermittent hydrarthrosis, in which the hydrarthrosis recurred at regular intervals over a period of five months, seventeen years after the initial $\mathrm{Br}$. melitensis infection. More recently Professor S. Weil ${ }^{4}$ has reported a case of hydrarthrosis of the foot due to Malta fever, pointing out that this may occur either during the febrile period or long after its resolution. By way of comparison it is interesting to find $Z$ drodowski ${ }^{5}$ quoting 17.5 per cent. bone or joint lesions occurring in guinea-pigs experimentally inoculated with $\mathrm{Br}$. abortus. A case has also been reported from. Barcelona ${ }^{6}$ in which a spontaneous fracture occurred as a sequel to a $\mathrm{Br}$. melitensis infection. Most of these authors appear to agree that it is rare for these bone and joint lesions to leave permanent disability.

As little has been published on this subject in British medical literature, it is thought that this case may be of interest, since here osteitis and hydrarthrosis coexist in the same patient. 